\title{
First Record of the African Wall Gecko, Tarentola ephippiata O'Shaughnessy 1875 (Phyllodactylidae) in North America
}

\author{
Tasman Rosenfeld, Prestin Tomborello, and Nick Ziegler
}

Department of Geology and Geophysics, Yale University, New Haven, Connecticut 06511, USA (tasman.rosenfeld@yale.edu)

A Il but three of the 21 currently recognized species in genus Tarentola reside in the Mediterranean Basin of Europe and North Africa or on Macaronesian Islands off the Atlantic coast of northern Africa (Rato et al. 2012). The three exceptions include the American Wall Gecko (T. americana), which is native to Cuba and The Bahamas (Rato et al. 2012), and the Oriente Wall Gecko (T. crombiei) and Jamaican Giant Gecko (T. albertschwartzi) from Cuba and Jamaica, respectively (Diaz and Hedges 2008; Sprackland and Swinney 1998). Non-native populations of the White-spotted Wall Gecko (T. annularis) and the Common Wall Gecko (T. mauritanica) have been recorded in southern Florida (e.g., Krysko et al. 2016).

Loveridge (1947) suggested Tarentola ephippiata and T. annularis were geographic races of a single species, but a later morphological analysis by Grandison (1961) demonstrated that they were, as originally described, distinct sympatric species native to parts of northcentral and northwestern Africa. Indeed, confusion between the two species in collections and presumably in the wild is warranted as the two taxa are superficially very similar. However, distinguishing characters noted by Grandison (1961) included a disparity between number of teeth in neonates and adults of both species and, most apparent at first glance, dorsal patterns, with T. ephippiata described as having "ladder-like arrangements of red or brown crescents stretching from the nape to the base of the tail."

Herein we report the first record of an African Wall Gecko from the state of Florida and the continent of North America. At 0002 h on 25 June 2019, while searching for lizards during a separate project permitted by the Florida Fish and Wildlife Conservation Commission, PT observed by flashlight and photographed a lone lizard that the authors initially thought was an aberrant $T$. annularis but was later

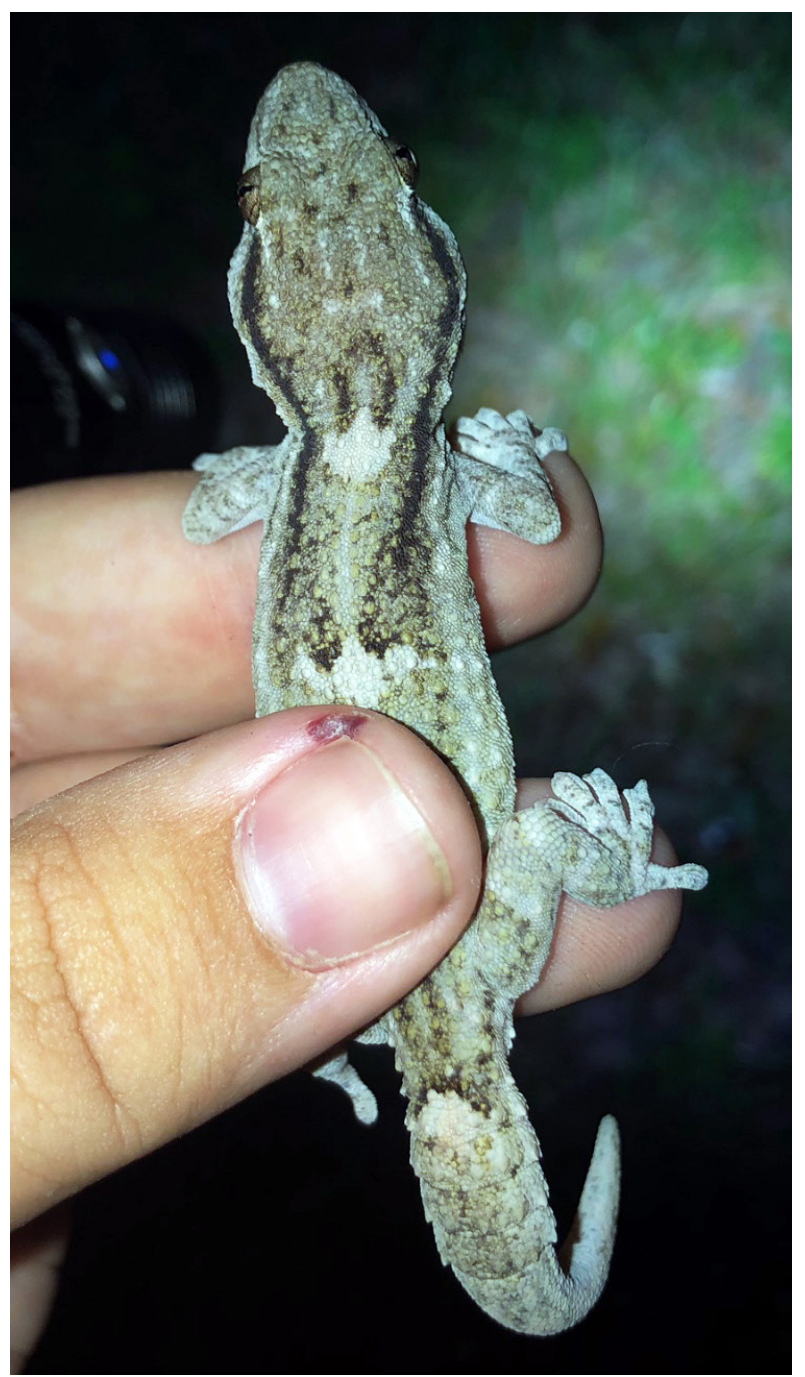

Fig. 1. Dorsal view of an adult African Wall Gecko, Tarentola ephippiata (UF-Herpetology 188725), from Davie, Broward County, Florida. Photograph by Prestin Tomborello. 
identified as T. ephippiata by Aaron M. Bauer (Fig. 1). The specimen was deposited in the Florida Museum of Natural History (UF-Herpetology 188725).

The gecko was on an approximately $2-\mathrm{m}$ tall chainlink fence along the edge of an empty suburban lot $\left(26.0455895^{\circ} \mathrm{N},-80.2193010^{\circ} \mathrm{W}\right.$; Datum WGS84) in the vicinity of a warehouse of a pet dealer credited with the introduction of numerous nonnative reptilian and amphibian species (Krysko et al. 2016). The lot consisted of a lawn of primarily St. Augustine and other short grasses with oaks and sea grape trees on the southern and southwestern perimeter hanging over the fence on which the lizard was found. Given the locality of the encounter and the other exotic species observed, we suggest that the introduction of T. ephippiata to this site was due to the accidental or intentional release of a captive animal by the pet dealer or a private keeper.

The presence of a single non-gravid individual of a species not known to be parthenogenic likely represents a stage-II introduction (sensu Colautti and MacIsaac 2004). Eradication by rapid response could be successful, although foliage and private property pose challenges.

\section{Acknowledgments}

We thank Mike R. Rochford for his guidance in writing our first record for publication.

\section{Literature Cited}

Colautti, R.I. and H.J. MacIsaac. 2004. A neutral terminology to define 'invasive' species. Diversity and Distributions 10: 135-141.

Díaz, L.M. and S.B. Hedges. 2008. A new gecko of the genus Tarentola (Sauria: Gekkonidae) from eastern Cuba. Zootaxa 1743: 43-52.

Grandison, A.G.C. 1961. Preliminary notes on the taxonomy of Tarentola annularis and T. ephippiata (Sauria: Gekkonida). Zoologische Mededelingen 38: 1-14

Krysko, K.L., L.A. Somma, D.C. Smith, C.R. Gillette, D. Cueva, J.A. Wasilewski, K.A. Enge, S.A. Johnson, T.S. Campbell, J.R. Edwards, M.R. Rochford, R.T. Thompkins, J.L. Fobb, S. Mullin, C.J. Lechowicz, D. Hazelton, and A. Warren. 2016. New verified nonindigenous amphibians and reptiles in Florida through 2015, with a summary of over 152 years of introductions. Reptiles and Amphibians 23: 110-143.

Loveridge, A. 1947. Revision of the African lizards of the family Gekkonidae. Bulletin of the Museum of Comparative Zoology 98: 1-469.

Rato, C., S. Carranza, and D.J. Harris. 2012. Evolutionary history of the Genus Tarentola (Gekkota: Phyllodactylidae) from the Mediterranean Basin, estimated using multilocus sequence data. BMC Evolutionary Biology 12: 14 (doi:10.1186/1471-2148-12-14).

Sprackland, R.G. and G.N. Swinney. 1998. A new species of giant gecko of the genus Tarentola (Reptilia: Squamata: Gekkonidae) from Jamaica. Journal of Zoology 245: 73-78. 